\section{An alternative view of Falkland conservation}

While much concern has been expressed in high places about the supposed vulnerability of Falkland wildlife to recent events, few people appear to have had the time, knowledge, opportunity or inclination to study and report on it in detail, so that many of these alarmist statements are regrettably imprecise. The current military activity provided an obvious opportunity to learn more of a neglected area, so I took advantage of a tour as a ship's doctor to attempt an independent appraisal. While it may not provide as full a picture as Ian Strange and Simon Lyster in the January Oryx, it has a different perspective.

In the first place, I was rather surprised that people should be so concerned about the impact of a military presence on the islands, since at home where the main threat comes from subsidised agriculture the armed services are usually rather helpful. As we approached the islands it emerged that they are currently so much more frightened of local critics, who claim that everything in sight from a mountain to an old boat is so fragile that it is about to disintegrate, than foreign enemies, that this helpfulness currently takes the form of placing everywhere interesting out of bounds and making it necessary to obtain 48 hours' clearance in advance before visiting anywhere else outside Stanley, which automatically precludes landings from patrolling vessels.

Eventually after visiting local naturalists we applied to the military authorities for permission to visit the small and apparently rather ordinary but ornithologically unexplored tussock islet next to our anchorage in San Carlos Water, which is used for grazing stock, apparently has no military importance, and had been visited by other people with the approval of the landowner, and were surprised to be refused without explanation. It took so long to get this reversed that eventually we never got there or bothered to try anywhere else. Fortunately I was more interested in the behaviour of birds at sea.

In view of this exaggerated concern for peripheral sites it was rather surprising to find nobody particularly worried by the rampant uncontrolled development now taking place in Stanley, 116 although in view of agricultural trends one certainly wonders what will happen when it extends to the countryside (or 'camp'). In general, it appeared that while most of the surviving wildlife was still flourishing despite the emergency, there is clearly a serious need for more information on which to base a conservation programme in advance of this development whose character will be determined locally although we shall be asked to pay for it.

In the circumstances it really does not seem very sensible to go around crying 'havoc' and attempting to repel the dogs of war when all they wish to do is a bit of sightseeing of a type that would be allowed at home after defending the place, and their helpfulness could be turned to more useful purposes than placing the whole countryside (which in point of fact is largely free of mines away from Stanley) out of bounds. It would be interesting to know quite who is trying to stop people getting around like this.

W.R.P. Boume, 3 Contlaw Place, Milltimber, Aberdeen AB1 ODS, UK

\section{SPECIAL OFFER}

\section{Snow leopard prints}

Prints are now available of Jim Channell's beautiful painting of the endangered Snow Leopard. Size: $501 / 2 \mathrm{~cm} \times 42 \mathrm{~cm}$ (actual picture size: $401 / 2$ $\mathrm{cm} \times 34 \mathrm{~cm}$ ). Individually signed by artist.

Price: $£ 13.50$ (includes p. and p.-rolled in strong tube)

\section{Collins Field Guides}

Collins Pocket Guide to Nests and Eggs

R.S.R. Fitter and R.A. Richardson

Collins Pocket Guide to Wild Flowers

David McClintock and R.S.R. Fitter

The Wild Flowers of Britain and Northem Europe

R.S.R. Fitter, Alastair Fitter and Marjorie Blamey

The Complete Guide to British Wildlife

N. Arlott, R.S.R. Fitter and Alastair Fitter

Price: $£ 4.95$ (price includes p. and p.)

\section{DON'T FORGET:}

\section{Oryx binders}

New, loose-leaf Oryx binders are available (holds two volumes)

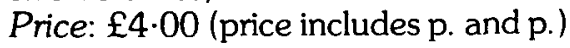

Oryx Vol 18 No 2 